\title{
Zebrafish models of inherited retinal dystrophies
}

\author{
Brian D. Perkins ${ }^{1,2,3}$ \\ 'Department of Ophthalmic Research, Cole Eye Institute, Cleveland Clinic, OH 44195, USA. \\ ${ }^{2}$ Department of Ophthalmology, Cleveland Clinic Lerner College of Medicine, Case Western Reserve University, OH 44195, USA. \\ ${ }^{3}$ Department of Molecular Medicine, Cleveland Clinic Lerner College of Medicine, Case Western Reserve University, Cleveland, \\ $\mathrm{OH} 44195$, USA. \\ Correspondence to: Dr. Brian D. Perkins, Department of Ophthalmic Research, Cole Eye Institute, Cleveland Clinic, 9500 Euclid \\ Ave, Cleveland, OH 44195, USA. E-mail: Perkinb2@ccf.org
}

How to cite this article: Perkins BD. Zebrafish models of inherited retinal dystrophies. J Trans/ Genet Genom 2022;6:95-110. https://dx.doi.org/10.20517/jtgg.2021.47

Received: 23 Sep 2021 First Decision: 27 Sep 2021 Revised: 30 Oct 2021 Accepted: 22 Nov 2021 Published: 8 Feb 2022

Academic Editor: Bernhard HF Weber Copy Editor: Xi-Jun Chen Production Editor: Xi-Jun Chen

\begin{abstract}
Inherited retinal degenerations (IRDs) cause permanent vision impairment or vision loss due to the death of rod and cone photoreceptors. Animal models of IRDs have been instrumental in providing knowledge of the pathological mechanisms that cause photoreceptor death and in developing successful approaches that could slow or prevent vision loss. Zebrafish models of IRDs represent an ideal model system to study IRDs in a cone-rich retina and to test strategies that exploit the natural ability to regenerate damaged neurons. This review highlights those zebrafish mutants and transgenic lines that exhibit adult-onset retinal degeneration and serve as models of retinitis pigmentosa, cone-rod dystrophy, and ciliopathies.
\end{abstract}

Keywords: Retina, photoreceptors, zebrafish, regeneration, degeneration, cilia

\section{INTRODUCTION}

Inherited retinal degenerations (IRDs) comprise a large collection of diseases that progressively compromise vision and can lead to blindness due to the degeneration of rod and cone photoreceptors. IRDs exhibit genetic and clinical heterogeneity, with 280 unique disease genes identified to date ${ }^{[1]}$. The inheritance patterns of IRDs include autosomal dominant, autosomal recessive, and X-linked, although mutations in mitochondrial DNA have been shown to cause retinopathy. Diseases such as retinitis pigmentosa (RP), 
cone-rod dystrophy, Leber congenital amaurosis (LCA), and choroideremia affect the eye alone. RP is also associated with several syndromic and systemic conditions, where the disease impacts one or more other organs. These diseases can include Usher syndrome, in which RP is associated with hearing loss, Joubert syndrome (JBTS) and Bardet-Biedl syndrome (BBS), which are two ciliopathies with systemic effects, and Senior-Loken syndrome, which presents with RP and kidney disease. It was recently estimated that approximately 5.5 million people worldwide ( 1 in 1380 people) are afflicted by $\operatorname{IRDs}^{[2]}$ and this has a significant cost on both individuals and society. The financial impact of IRDs associated with economic and wellbeing costs was estimated to range between \$13-31 billion in the United States and between CAN\$6691638 billion in Canada for $2019^{[3]}$.

Until recently, no therapeutic options existed that could slow or reverse the disease progression of IRDs. The ongoing success in identify the genetic causes of IRDs has allowed strategies such as gene therapy and genome editing to show promise and early success ${ }^{[4-6]}$. While encouraging, gene augmentation and gene correction strategies still require that most therapies be specifically tailored to each genetic mutation or mutated exon, of which there are thousands. To circumvent these limitations, there has been considerable interest in strategies that promote tissue regeneration either through stem cell transplantation ${ }^{[7,8]}$ or regeneration from endogenous stem cell populations ${ }^{[9,10]}$. Although adult mammals show limited potential for endogenous retinal regeneration ${ }^{[1,12]}$, zebrafish readily regenerate their retina after injury ${ }^{[13-15]}$ and restore visual function ${ }^{[16]}$. In zebrafish, the Müller glia respond to injury by reprogramming and re-entering the cell cycle to produce multipotent neural progenitors ${ }^{[1,1,17,18]}$. There is now considerable interest in exploiting this regenerative capacity for possible therapies for the treatment of IRDs. As no single therapeutic strategy will be a "magic bullet" for IRDs, including regenerative medicine, it remains essential to test any approaches in animal models that recapitulate human disease.

Since being established as an animal model for developmental genetics in the $1970 \mathrm{~s}^{[19,20]}$, zebrafish have become increasingly popular as a disease model, including as a model for IRDs ${ }^{[21-28]}$. Investigators initially used genetic screens of fish mutagenized by ethylnitrosourea (ENU) to identify dozens of mutants with defects in retinal structure and function ${ }^{[29-33]}$. Simple histological methods $s^{[31,34,35]}$ and visual behaviors, such as the optokinetic response $(\mathrm{OKR})^{[29,30]}$, were highly successful at identifying novel mutant phenotypes in larval zebrafish and ultimately discovering factors important for protein trafficking ${ }^{[36]}$, cone phototransduction ${ }^{[37,38]}$, retinal development ${ }^{[39,40]}$, and many others. Interestingly, almost all of these mutations affects cones or cones and rods and the large majority were lethal within the first two weeks of age. Why would impaired vision result in lethality? Insight comes from the study of the no optokinetic response $f$ (nof) mutant, which was identified in ongoing screens for mutants that lacked an OKR behavior $^{[38]}$. The nof mutation introduced a stop codon in the alpha subunit of cone transducin, leading to complete loss of protein. The nof mutants were morphologically indistinguishable from their wild-type siblings and no evidence of retinal degeneration was observed. Nevertheless, the nof larvae did not survive beyond $12 \mathrm{dpf}$ under standard rearing conditions. If the mutants were raised in a "soup" containing a 10fold higher concentration of paramecium, a large number survived to adulthood. The conclusion was that loss of cone function impaired the ability of larvae to effectively hunt paramecia using visual cues and feed during the first few weeks of life. In other words, severe visual impairment leads to starvation under standard laboratory rearing conditions. A notable exception was the early search for dominant forms of retinal degeneration in zebrafish by Li and Dowling ${ }^{[33]}$. In this study, the investigators used the "escape response" behavior assay to screen for mutants. Zebrafish swim in circles when placed in a small, circular container but will rapidly turn and swim in the opposite direction when challenged. F1 animals (i.e., heterozygotes) derived from ENU mutagenized founders were dark adapted and screened for elevated visual thresholds to identify mutants. The night blindness a $(n b a)$ mutant exhibited elevated visual thresholds and 
progressive degeneration of rods and cone $e^{[33]}$. The identity of the $n b a$ gene remains unknown, but this was the first reported mutant with adult-onset retinal degeneration in zebrafish. As ENU creates numerous lesions throughout the genome, it is important that all ENU-induced mutants be outcrossed for several generations to ensure the observed phenotypes reflect the mutation of a single locus. Genome editing technologies such as CRISPR/Cas9 now permit investigators to generate zebrafish with mutations in genes orthologous to human disease genes ${ }^{[1,42]}$ and other genes of interest. While most zebrafish mutants have been investigated primarily at the larval stage, a number of zebrafish mutants are viable into adulthood and show progressive photoreceptor degeneration. In contrast to the regeneration observed following acute injury, these mutants do not initiate a robust regeneration response to disease. The reasons for this difference remain unclear. The purpose of this review is to examine those zebrafish mutants that are adultviable and exhibit progressive retinal degeneration. Studies of zebrafish mutants with photoreceptor dysfunction during larval stages have provided valuable information regarding photoreceptor biology; however, in order to harness the capacity for regeneration in a diseased retina, it will be critical to investigate zebrafish models that mimic the pathology and progressive degeneration observed in human IRDs. Several recent reviews provide excellent discussions of regeneration ${ }^{[43-46]}$ and of zebrafish mutants with retinal degeneration ${ }^{[22,27,47-49]}$.

\section{ZEBRAFISH MODELS OF RETINAL DEGENERATION}

Several zebrafish models of retinal dystrophy exist. In some cases, retinal degeneration is induced by damage caused by cytotoxic compounds $s^{[16,50,51]}$, acute light exposure ${ }^{[14]}$, or mechanical injury ${ }^{[15]}$ for the purposes of studying regeneration. This review will focus on genetic models with progressive retinal degeneration in adults and will include both transgenic lines and zebrafish mutants with mutations in genes that cause retinal dystrophy in humans.

\section{Zebrafish mutant models of progressive retinal dystrophy}

Abelson-helper integration site-1

Mutations in the Abelson-helper integration site-1 (AHI1) gene result in JBTS ${ }^{[2,53]}$. JTBS is an autosomal recessive ciliopathy noted for a characteristic brain-stem abnormality known as the "molar tooth" sign, as well as retinal dystrophy. The AHI1 gene encodes a protein component of the ciliary transition zone (TZ) that functions as a diffusion barrier between the photoreceptor inner segment and outer segment ${ }^{[5,55]}$. The zebrafish $a h i 1^{\text {lrit6 }}$ mutant exhibited disorganized cone outer segments during larval stages but visual function as assessed by OKR assays was not impaired at 5 days post fertilization ${ }^{[41]}$. More than $95 \%$ of zebrafish ahi1 mutants died before 3 months post fertilization (mpf). Among surviving animals, cone photoreceptor structure was normal at $3 \mathrm{mpf}$ but rapidly degenerated by $5 \mathrm{mpf}$. Rod photoreceptors exhibited rhodopsin mislocalization but a net loss of rods was not observed, suggesting that rods were unhealthy but degeneration was limited.

\section{Aryl hydrocarbon receptor interacting protein-like 1}

Mutations in the aryl hydrocarbon receptor interacting protein-like 1 (AIPL1) gene result in LCA, although individuals heterozygous for a 12-bp deletion were diagnosed with either a dominant form of juvenile retinitis pigmentosa or autosomal dominant cone-rod dystrophy ${ }^{[5]}$. AIPL1 is expressed in exclusively in rod photoreceptors of both the peripheral and central retina in humans ${ }^{[57]}$. Aipl1 protein functions as part of an HSP90 chaperone complex ${ }^{[58]}$ that facilitates maturation of farnesylated proteins such as the cGMP phosphodiesterase 6 subunits $\alpha$ and $\beta^{[59,60]}$. The zebrafish gold rush (gosh) mutant was identified in a largescale mutagenesis screen for ENU-induced recessive mutations that disrupt visual behavior in zebrafish larvae ${ }^{[32]}$. Visual function was completely absent in gosh mutants and cone photoreceptors were disorganized with shorter outer segments at $7 \mathrm{dpf}$. By $4 \mathrm{wpf}$, the ONL was thinner and green cones were 
absent. Cones were almost completely absent by $12 \mathrm{wpf}$ and the number of neurons in all layers of the retina were decreased. Rods continued to be maintained, although rhodopsin staining was reduced compared to wild-type siblings. Interestingly, proliferation of rod precursors in the ONL of gosh mutants was observed beginning at $5 \mathrm{wpf}^{\left[{ }^{[1]}\right]}$. There was also a small increase in the number of proliferating Müller glia in the INL of gosh mutants. Subsequent genetic mapping of the gosh locus identified an aipl gene as a candidate for the gosh mutant. Sequencing of this gene uncovered a nonsense mutation. The zebrafish genome contain two aipl1 orthologs, aiplia and aipl1b. The aipl1a gene is more similar to human AIPL1. The gosh mutant was caused by a mutation in the aipllb gene. Expression of aipl $1 b$ was restricted to cones, whereas aiplia was expressed in rods and likely UV cones. The cone-specific expression of aiplib likely explains why cones degenerated in gosh mutants. Cones degenerated rapidly in gosh mutants but rods also begin degenerating by 3 weeks post fertilization, indicating that $a i p l 1 b$ is necessary for both cone and rod survival ${ }^{[61]}$. A followup study found that the rapid degeneration of cones triggered a modest proliferation of Müller glia and rod degeneration resulted in proliferation of rod precursors. Within the INL, the proliferating Müller glia expressed Sox2 and the neural progenitors expressed Pax6. Individual Pax6+ cells appeared to migrate to the ONL. Given that the proliferating Müller glia did not result in cone regeneration, it is possible that the Pax6+ neural precursors were rod progenitors en route to the ONL to provide additional rod precursors and attempt to regenerate rods ${ }^{[62]}$.

\section{$\mathrm{BBS} 2$}

BBS is clinically and genetically heterogeneous autosomal recessive disorder characterized by retinal degeneration, obesity, renal dysfunction, polydactyly, and mental retardation ${ }^{[6,64]}$. To date, mutations in 22 genes have been shown to cause $\mathrm{BBS}^{[65]}$. BBS2 encodes a core protein of the BBSome ${ }^{[6 \sigma]}$, which is an octomeric protein complex required for protein trafficking through the photoreceptor cilium ${ }^{[6,68]}$. The $b b s 2^{\text {risz }}$ mutant was generated by CRISPR/Cas9 mutagenesis and exhibited impaired OKR responses and shortened cone outer segments at $5 \mathrm{dpf}^{[69]}$. The bbs2 mutants lived into adulthood, but were smaller and exhibited spinal curvatures that are consistent with ciliopathy phenotypes in zebrafish ${ }^{[70]}$. In adult $b b s 2$ mutants, cone photoreceptors degenerated and rods exhibiting rhodopsin mislocalization. A significant increase in proliferating cells within the outer nuclear layer of adult bbs2 mutants suggested that rods were being regenerated from rod precursors. No proliferation of Müller glia was observed in bbs2 mutants, indicating that the regeneration typically seen following acute injury did not occur. The lack of Müller glia proliferation was not due to the bbs2 mutation, as acute light injury was capable of triggering a regeneration response in both bbs2 mutants and wild-type siblings.

\section{Centrosomal protein $290-k D$}

The centrosomal protein 290-kD gene (CEP290) encodes a large, multidomain coiled-coil protein that localizes to the ciliary TZ and to the centrosome/basal body in motile and non-motile cilia ${ }^{[71-73]}$. As a component of the TZ, Cep290 regulates protein trafficking through the cilium ${ }^{[74]}$ and facilitates ciliary assembly ${ }^{[7,76]}$. In humans, more than 130 mutations in CEP290 have been shown to cause a variety of ciliopathy disorders, including JBTS, BBS, Senior-Loken syndrome, Meckle syndrome, and nephronophthisis ${ }^{[77,78]}$, with retinal dystrophy being a common symptom. Mutations in CEP290 can also result in non-syndromic retinal degenerations such as early-onset $\mathrm{LCA}^{[79]}$ and late-onset $\mathrm{RP}^{[80]}$. Despite several years of intense study on CEP290 genetics in humans and in animal models, no consensus exists to explain CEP290 pleiotropy or to establish genotype-phenotype correlations. Three distinct zebrafish cep290 mutant lines have been described in the literature. The cep $290^{\text {fh } 297}$ allele is a nonsense point mutation (p.Gln1217X) that was induced by ethynitrosourea (ENU) $)^{[81]}$. The cep29 fh297 mutant had normal visual function by OKR assays and normal photoreceptor structure at $5 \mathrm{dpf}^{[81]}$. The cep290 $0^{f / 378}$ mutant allele was made using TALEN genome editing and resulted in a $2 \mathrm{bp}$ deletion that produces a downstream stop codon 
after amino acid $99^{[82]}$. No retinal phenotype was described for $c e p 290^{f_{378}}$. The $c e p 290^{f b 208}$ mutant allele is a 10 bp deletion in exon 16 generated by CRISPR/Cas9 mutagenesis and results in a premature stop codon $^{[83]}$. Cardenas-Rodriquez and colleagues generated maternal-zygotic (MZ) cep290 $0^{f b 208}$ mutants, which lack maternally-derived mRNA and protein in the yolk of zebrafish embryos and larvae, to exclude the possibility that the presence of maternal Cep290 protein could mask phenotypes during larval stages ${ }^{[83]}$. MZcep29 ${ }^{f b 208}$ mutants also exhibited normal vision as assessed by electroretinograms but did show mild disorganization of outer segments and an accumulation of vesicular material at the base of the outer

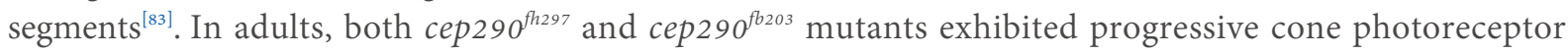
degeneration, with the cep $290^{f h 297}$ mutant losing approximately $40 \%$ of cones by $6 \mathrm{mpf}$ and $80 \%$ of cones by 12 mpf. Rhodopsin mislocalized to the inner segments of rod photoreceptors. The proliferation of rod precursors in the ONL suggested that rods degenerated in the cep $290^{f h 297}$ mutant ${ }^{[81]}$. Similar to what was observed in the bbs2 mutant, Müller glia did not proliferate in the cep $290^{\text {fh297 }}$ mutants. Analysis of Müller cell proliferation or rod degeneration was not performed for the $M Z c e p 290^{f b 208}$ mutants.

\section{Ceramide kinase-like}

The ceramide kinase-like (CERKL) gene encodes a 532 amino acid polypeptide that contains a pleckstrin homology $(\mathrm{PH})$ and a diacylglycerol kinase (DAGK) domain ${ }^{[84]}$. CERKL is a member of the ceramide kinase protein family, which converts ceramide to ceramide-1-phosphate, but CERKL has not yet been shown to possess enzymatic activity ${ }^{[85,86]}$. CERKL is expressed throughout the retina, as well as brain, lung, liver, kidney, and pancreas ${ }^{[8]}$. Despite this widespread expression pattern, mutations in CERKL have only been associated with nonsyndromic $\mathrm{RP}^{[84]}$ and with cone-rod dystrophy ${ }^{[87]}$. A cerkl knockout zebrafish (cerkl ${ }^{\text {hzus }}$ ) was generated by TALEN technology and resulted in a 7 bp deletion that caused a premature nonsense mutation. Visual impairment was detected in $7 \mathrm{dpf}$ cerkl larvae by ERG analysis ${ }^{[88]}$. Thinning of the ONL was observed as early as $2 \mathrm{mpf}$, with continued thinning at $4 \mathrm{mpf}$ and a significant loss of photoreceptors by $12 \mathrm{mpf}$. Immunohistochemical and western blotting analyses indicated that rod photoreceptor degeneration preceded the degeneration of cones, suggesting that the cerkl mutant represents an ideal model for RP. Cell proliferation was not assessed for the cerkl mutant, so it remains unclear if the rod precursors or Müller glia attempt to regenerate photoreceptors. The mechanisms underlying photoreceptor degeneration due to loss of CERKL function remain unclear and future studies of the cerkl zebrafish mutant may provide unique insight.

\section{Eyes shut}

The eyes shut (EYS) gene encodes a large extracellular matrix protein of 3165 amino acids that is the homolog of the Drosophila eyes shut gene. Mutations in EYS are a major cause of autosomal recessive RP in humans across the world and account for the most prevalent form of RP in Japanese population ${ }^{[8,9,0]}$. EYS is highly expressed in the human retina but expression is absent in the retinas of mouse, rat, and cattle ${ }^{[91]}$, thus limiting the study of EYS function in the retina. To address this limitation three groups independently generated mutations in the zebrafish eys gene. Yu et al. ${ }^{[92]}$ used CRISPR/Cas9 to generate multiple mutants with truncating nonsense alleles in exon 2 of the eys gene. Three alleles, eys $s^{\text {snylo }}$, eys ${ }^{\text {snyl }}$, and eys $s^{\text {sny } 14}$, had identical phenotypes of cone degeneration beginning between 4-6 mpf and slower rod degeneration that was apparent by $14 \mathrm{mpf}$. Using antibodies specific for EYS, the group also reported that EYS protein concentration near the connecting cilium and transition zone of the photoreceptors in both zebrafish and primate retinas. Using TALEN technology, Lu et al. ${ }^{[93]}$ independently generated several truncating nonsense alleles in exon 47 of the zebrafish eys gene. ERG analysis at $10 \mathrm{dpf}$ revealed a significant decrease in b-wave amplitude in eys mutants, indicating visual impairment. In these mutants, a decrease in ONL thickness was noticed as early as $2 \mathrm{mpf}$, with more than $60 \%$ reduction by $16 \mathrm{mpf}$. Interestingly, cone subtypes differed in the rate of degeneration. Lu et al. ${ }^{[93]}$ reported that the number of red and UV cones decreased significantly 
by $4 \mathrm{mpf}$, while green and blue cones were only partially reduced by $8 \mathrm{mpf}$. It is unclear why zebrafish with mutations in exon 47 would exhibit more rapid degeneration of cones and the selective loss of red and UV cones, when compared to zebrafish with mutations in exon 2. More recently, Messchaert et al. ${ }^{[94]}$ used CRISPR/Cas9 technology to generate a 5-bp deletion in exon 20 of eys. Immunohistochemistry with antiEYS antibodies on retinas from the eys ${ }^{r m c 101}$ mutant showed a complete loss of protein, indicating this was a null allele. In $5 \mathrm{dpf}$ larvae, the eys $\mathrm{s}^{\text {rmc1o1 }}$ mutant was reported to have shorter and more disorganized photoreceptor outer segments than wild-type siblings, but no quantification was provided. By $2 \mathrm{mpf}$ a significant thinning of the INL and ONL was observed. Rhodopsin and the alpha subunit of cone transducin were mislocalized in rods and cones, respectively by $5 \mathrm{mpf}$. The authors also explored Müller glia morphology and did not observed evidence of gliosis or Müller glia proliferation. Of note, however, was that eys ${ }^{r \text { mc101 }}$ mutants had normal OKR behavior but a decrease in the ERG b-wave, which strongly suggested an early defect in visual function as early as $5 \mathrm{dpf}$. All three groups reported that eys mutants exhibited photoreceptor degeneration that starts by $2 \mathrm{mpf}$ and progresses with age. Additional investigation with these mutants will help reveal the cellular function of EYS in photoreceptors and explain the mechanisms leading to photoreceptor death.

\section{Photoreceptor cilium actin regulator}

Two groups independently identified mutations in the centrosome 2 open reading frame 71 (C2ORF71) gene that result in non-syndromic autosomal recessive RP in families of various national origins ${ }^{[95,96]}$. C2ORF71 is exclusively expressed in the retina ${ }^{[95]}$. Recent work demonstrated that the protein encoded by $\mathrm{C}_{2} \mathrm{ORF} 7 \mathrm{1}$ interacts with several proteins associated with centrioles, microtubules, and factors that regulate actin filament assembly ${ }^{[97]}$. Based on these findings, Corral-Serrano et al. ${ }^{[97]}$ proposed that $C 2 O R F 71$ be renamed PCARE for photoreceptor cilium actin regulator. The zebrafish genome contains two pcare paralogs, pcare 1 and $p c a r e 2^{[98]}$. By searching for synteny between the chromosomal region of the human PCARE gene and the zebrafish genomes, the pcare1 gene was considered to be the ortholog of the human gene. A zebrafish pcare1 mutant line was generated by CRISPR/Cas9 mutagenesis and the $29 \mathrm{bp}$ deletion was predicted to result in a truncating nonsense allele at amino acid $16^{[98]}$. Mutants exhibited disrupted actin assembly and disorganized photoreceptor structure as early as $5 \mathrm{dpf}$. The pcare 1 mutants were viable and at $6 \mathrm{mpf}$, the rod outer segments were highly disorganized or missing and cone outer segments were significantly shorter than wild-type siblings ${ }^{[98]}$. This is consistent with the RP phenotype in humans. The rapid degeneration of rods seen in pcare1 mutants would suggest that proliferation of Müller glia or rod precursors may occur, although this was not investigated. Future studies of the pcare1 mutant could explore whether a regenerative response follows the degeneration of photoreceptors, while functional studies of pcarez may uncover a similar role in photoreceptor maintenance.

\section{Phosphodiesterase 6}

Photoreceptors respond to light by activating a G-protein signaling pathway known as the phototransduction cascade ${ }^{[99,100]}$. Upon absorption of a photon of light, rhodopsin or cone opsins activate many molecules of the heterotrimeric G-protein transducin. The GTP-bound $\alpha$-subunit of transducin $\left(\mathrm{G}_{\mathrm{t}}\right)$ activates its effector enzyme, cGMP phosphodiesterase 6 (PDE6). PDE6 hydrolyzes cGMP, resulting in a decrease in cGMP concentration and the closure of cGMP-gated channels in the outer segment plasma membrane. PDE6 is a multimeric enzyme. The rod-specific PDE6 is a heterotetramer, consisting of a $\alpha$ subunit, $\beta$-subunit, and two $\gamma$-subunits. The cone PDE6 consists of two cone-specific $\alpha^{\prime}$-subunits and two cone-specific $\gamma$-subunits. The cone-specific $\alpha^{\prime}$-subunits are encoded by the PDE6C gene ${ }^{[101]}$, Mutations in the rod-specific $P D E 6 A$ gene cause $\mathrm{RP}^{[102]}$ while mutations in $P D E 6 C$ result in cone dystrophy and achromatopsia ${ }^{[103,104]}$. Nishiwaki et al. ${ }^{[105]}$ conducted a genetic screen for zebrafish with defects in visual behavior and identified several mutants, including eclipse (els). The els mutant exhibited irregular 
photoreceptor structure and a complete absence of the ERG b-wave. Subsequent mapping and cloning of the eclipse locus identified a missense mutation in the pde6a' ( $p d e 6 c)$ gene that resulted in a Met175Arg amino acid substitution. They found that $p d e 6 \mathrm{c}$ was expressed in cones and that cones degenerated rapidly. Despite the lack of functional cone vision, the mutants survived into adulthood. Few cones remained at $3 \mathrm{wpf}$ and although rod morphology was compromised at $3 \mathrm{wpf}$, the rods remained functional. By $6 \mathrm{mpf}$, rods appeared normal but cones were absent from the central retina ${ }^{[106]}$. As early at $5 \mathrm{wpf}$, the number of proliferating cells $(\mathrm{BrdU}+)$ was increased in both the INL and ONL of the pde6c mutants. At 5 wpf, however, the retina continues to rapidly expand and add new rods into the cone mosaic as the fish grows. It is unclear if the proliferation observed in the pde6c mutants reflects an attempt to regenerate dying rods, the expansion of rod numbers as the fish grows, or a combination of both. The significant increase in proliferating cells within the INL, however, may suggest a regenerative response due to the rapid degeneration of cones. Recently, a mutation in the rod-specific pde6a gene was reported ${ }^{[107]}$. This mutant had been generated by ENU mutagenesis and identified at the European Zebrafish Resource Centre. The mutation introduced a stop codon that produced a truncated protein at glutamine 70 ( $\left.p d e 6 a^{Q 70 X}\right)$. Disruption of pde6a did not result in OKR defects at $5 \mathrm{dpf}$, as the OKR is a cone-driven response ${ }^{[29]}$. The visual motor response (VMR) assay measures the locomotor activity of larvae to rapid light-dark change $^{[108]}$. In VMR assays, the pde6 a mutant had reduced VMR responses, suggesting impaired ability to detect light. Mutation of pde6a resulted in a reduction in rod size at $5 \mathrm{dpf}$ and an almost complete absence of rods by $21 \mathrm{dpf}$. Cone numbers were reduced slightly at $21 \mathrm{dpf}$, but morphology appeared normal ${ }^{[107]}$. No results were reported for later ages. Future studies will be needed to determine the long-term effect of $p d e 6 a$ loss on cones and whether the proliferation of cells in the INL of pde6c mutants can be enhanced to potentially regenerate cones.

$R P 2$

$\mathrm{X}$-linked retinitis pigmentosa (XLRP) can present as an aggressive and early form of RP that can occur within the first 4 years of life ${ }^{[109]}$. Mutations in the $R P 2$ gene were found to cause XLRP and these account for approximately $16 \%$ of all XLRP cases ${ }^{[110]}$. $R P 2$ encodes a 350 -amino acid protein that stimulates the GTPase activity of tubulin and also interacts with ADP-ribosylation factor-like-3 (ARL3) to stimulate its GTPase activity ${ }^{[11,112]}$. RP2 binds membranes and localizes to the cilium and photoreceptor membrane $\mathrm{e}^{[111,113]}$. Based on these observations, RP2 has been proposed to facilitate vesicular trafficking of proteins from the Golgi to the connecting cilium ${ }^{[113]}$. The zebrafish $r p 2$ knockout line was generated using TALEN genome editing ${ }^{[114]}$. The $r p 2$ mutants completely lack Rp2 protein and show mild visual impairment at $7 \mathrm{dpf}$ with a $30 \%$ reduction in the scotopic ERG b-wave compared to wild-type controls. Although mutants exhibited reduced visual function, no morphological differences appeared until $4 \mathrm{mpf}$, when rod outer segments were approximately $20 \%$ shorter. By $7 \mathrm{mpf}$, both rods and cones were shorter, consistent with a RP-like phenotype. Ultrastructural analysis of $10 \mathrm{mpf} r p 2$ mutants revealed that the rod outer segments were almost completely missing, while the remaining outer segments were disorganized. While the phenotype of the $r p 2$ mutant follows a progressive rod-cone dystrophy consistent with RP, it is worth noting that the rate of degeneration is quite slow compared to humans with $R P 2$ mutations. The $r p 2$ mutant may serve as a useful model to explore the mechanisms of photoreceptor degeneration and regeneration.

\section{Retinitis pigmentosa GTPase regulator interacting protein 1}

The retinitis pigmentosa GTPase regulator interacting protein 1 (RPGRIP1) gene encodes a 1259 amino acid protein with several alternatively spliced isoforms and was first identified as a binding partner to $\mathrm{RPGR}^{[115,116]}$. Mutations in $R P G R$ are responsible for the majority of cases of XLRP, while mutations in $R P G R I P 1$ result in $\mathrm{LCA}^{[117,18]}$ and cone-rod dystrophy ${ }^{[119]}$. RPGRIP1 is highly expressed in the retina, with weaker expression only found in the testis ${ }^{[116]}$. RPGRIP1 protein colocalizes with RPGR at the photoreceptor 
connecting cilium ${ }^{[120]}$, while some isoforms localize to the outer segments and other subcellular structures, including the nucleus ${ }^{[121]}$. RPGRIP1 is proposed to anchor RPGR at the connecting cilium where they likely function within the ciliary transition zone to regulate protein trafficking ${ }^{[122]}$. A zebrafish rpgrip1 mutant was made by ENU mutagenesis ${ }^{[123]}$. The zebrafish rpgrip1 contains 1342 amino acids and the mutation introduced a stop codon at amino acid 736 (Q736X). At $7 \mathrm{dpf}$, rod outer segments failed to form in rpgrip1 mutants, although cones were unaffected and the disk membranes appeared normal. Rhodopsin was mislocalized throughout the inner segments of the rpgrip1 mutant rods. Rods degenerated rapidly and only a few rod nuclei were present by $3 \mathrm{mpf}$. By $6 \mathrm{mpf}$, cone degeneration was apparent. Rod degeneration preceded the loss of cones, which is consistent with an RP model with rod-cone dystrophy rather than the cone-rod dystrophy seen in humans. By $13 \mathrm{mpf}$, both rods and cones had degenerated and few photoreceptor nuclei could be found within the presumptive ONL. Cell proliferation was not reported for the rpgrip1 mutant so future studies may explore whether rod precursors attempt to regenerate dying rods and whether the rapid degeneration triggers a response from Müller cells.

\section{RHODOPSIN}

Rhodopsin is the visual pigment of rod photoreceptors that absorbs photons of light to mediate vision. Rhodopsin is a proto-typical G-protein coupled receptor that binds the light-absorbing chromophore 11cis-retinal within the transmembrane region of the protein ${ }^{[124]}$. Mutations in the RHODOPSIN (RHO) gene are responsible for approximately $18 \%-26 \%$ of all adRP cases, which is far more than any other gene $\mathrm{e}^{[125-127]}$. Zebrafish possess two genes that encode rhodopsin, the $r h 1-1$ and $r h 1-2$ genes ${ }^{[128,129]}$. The protein product of the $r h 1-1$ gene shares strong homology with other vertebrate RHO proteins and the pattern of expression is consistent with function as the rod opsin gene. Multiple mutations in the zebrafish rhodopsin gene (rh1-1) were generated by CRISPR/Cas9 mutagenesis ${ }^{[42]}$. The $r h o^{f 6}$ allele encoded an N-terminal nonsense mutation at amino acid $17\left(\mathrm{~T} 17^{*}\right)$, which resulted in rod degeneration in homozygous animals as early as $5 \mathrm{dpf}$. Heterozygous animals for the $r h o^{f / 6}$ allele did not exhibit a phenotype, suggesting this mutation caused recessive rod degeneration. Two other $\mathrm{N}$-terminal mutations, the $r h o^{f t 7}$ and $r h o^{f l 1}$ alleles, encoded in-frame deletions that disrupted a highly conserved glycosylation sequence. Heterozygous larvae of both the rho ${ }^{f t}$ and $r h o^{f 10}$ alleles exhibited rapid rod degeneration by $6 \mathrm{dpf}$, consistent with a dominant rod degeneration. The $r h o^{f s}$ allele encodes an in-frame deletion in the C-terminus of the protein, while the $r h o^{f t}$ allele results in a nonsense mutation at amino acid $347\left(S 347^{*}\right)$. Heterozygous larvae of both alleles show loss of rods in the central retina. In adults, few rod photoreceptors were present and the rod outer segments were missing in heterozygous animals. These new zebrafish mutants will serve as useful models of both adRP while the $r h o^{f_{6}}$ allele could serve as model for autosomal recessive RP. Interestingly, the zebrafish cone photoreceptors were unaffected by the loss of rods. This differs from humans with RP-causing mutations in RHO, where rod degeneration results in the indirect death of cones. Future work may uncover novel mechanisms that permit cone survival in the absence of rods and reveal potential targets for therapies to preserve cones in patients with RP.

\section{Transgenic zebrafish models of retinal degeneration}

$\mathrm{Tg}$ (Xla.Rho:GAP-CFP) q13Tg

The first report of a model with rod-specific degeneration described a transgenic line of zebrafish that expresses a membrane-targeted cyan fluorescent protein (mCFP) using a $5.5 \mathrm{~kb}$ promoter sequence from the Xenopus laevis rhodopsin gene ${ }^{[130,131]}$. The mCFP protein included an N-terminal palmitoylation signal sequences from neuromodulin (GAP-43), which targets proteins to the plasma membrane ${ }^{[132]}$. This was originally named the $\mathrm{Tg}(X O P S: m C F P)$ transgenic line ${ }^{[130]}$. The Fadool lab had previously generated a transgenic line of zebrafish that expressed eGFP from the Xenopus rhodopsin promoter ${ }^{[133]}$. This $\mathrm{Tg}(X O P S: e G F P)$ line specifically labeled rods with eGFP and did not result in any deleterious effects on rod photoreceptors $^{[133]}$. In the $\mathrm{Tg}$ (XOPS: $m C F P$ ) line, however, rods exhibited an abnormal morphology shortly 
after the onset of transgene expression and most rods were missing by $5 \mathrm{dpf}$. Expression of the mCFP caused rhodopsin mislocalization to the inner segments and rapid degeneration. It is possible that the genomic integration sites of the $\operatorname{Tg}(X O P S: m C F P)$ transgene could have affected rod function, although this is considered unlikely. Zebrafish carrying the $\operatorname{Tg}(X O P S: m C F P)$ transgene survived into adulthood but lacked almost all rod photoreceptors. Cone photoreceptors survived into adulthood and cone morphology, and the cone mosaic appeared normal in the transgenic animals. This was the first indication that rod degeneration did not result in the secondary death of cones in zebrafish. The authors also noted an increase in the proliferation of rod precursor cells within the ONL of $\mathrm{Tg}$ (XOPS:mCFP) adults. The $\mathrm{Tg}(X O P S: m C F P)$ line has been instrumental in identifying the separate genetic pathways for rod and cone regeneration ${ }^{[134]}$, identifying genes important for rod regeneration ${ }^{[135]}$, and to demonstrate that an 11-cis-retinyl ester cycle is critical to maintain cone vision ${ }^{[136]}$.

Inducible rod death: Tg(rho:YFP-ntr)gmc50oTg, Tg(rho:Eco.NfsB-EGFP)nt19Tg, and Tg(rho:Eco.NfsBEGFP) nt2oTg

To study the effects of selective photoreceptor death in a controlled fashion, two groups independently generated transgenic lines that show rod-specific expression of the E. coli nitroreductase enzyme fused to a fluorescent reporter gene ${ }^{[137,138]}$. The nitroreductase enzyme (NTR, $n f_{s} B$ gene) reduces nitroimidazole prodrugs, such as metronidazole (MTZ), into cytotoxic metabolites that crosslink DNA and cause rapid death. When transgenic zebrafish are exposed to MTZ, any cells expressing NTR are selectively and specifically eliminated. Montgomery et al. ${ }^{[138]}$ first published the $T g(r h o: E c o . N f s B-e G F P) n t 19 T g$ and $\mathrm{Tg}(r h o: E c o . N f s B-e G F P) n t 20 \mathrm{Tg}$ alleles to investigate how rod death induces regeneration. Both lines utilize a $1.2 \mathrm{~kb}$ fragment of the zebrafish rhodopsin promoter to express a NTR-eGFP fusion protein specifically in rods. In the absence of MTZ, rods express NTR-eGFP and GFP fluorescence is visible in the rod outer segments and inner segments. Upon exposure to $10 \mathrm{mM} \mathrm{MTZ}$ for $24 \mathrm{~h}$, all the rods in the retinas of the $\mathrm{Tg}(r h o: E c o . N f s B-e G F P) n t 19 \mathrm{Tg}$ line rapidly degenerated within $48 \mathrm{~h}$. Despite carrying the identical transgene, the $\mathrm{Tg}$ (rho:Eco.NfsB-eGFP)nt2oTg transgenic line displayed NTR-eGFP expression in only a subset of rods. The genomic integration sites of the transgene most certainly differed between the $n t 19 \mathrm{Tg}$ and $n t 20 \mathrm{Tg}$ alleles and this may have influenced the expression patterns. When the $\mathrm{Tg}$ (rho:Eco.NfsB-eGFP)nt2oTg transgenic fish were exposed to MTZ for $24 \mathrm{~h}$, only those rods expressing NTR were destroyed and the non-expressing rods survived. The difference in damage between the two lines allowed the authors to compare how the retina responds to the loss of a subset of rods compared to the acute ablation of all rods photoreceptors. When a subset of rods was destroyed in the $T g(r h o: E c o . N f s B-e G F P) n t 20 T g$ transgenic line, rod precursor proliferation in the ONL was increased. The acute loss of all rods following MTZ treatment in $\mathrm{Tg}\left(r h o: E c o . N f_{s} B-e G F P\right) n t 19 \mathrm{Tg}$ transgenic animals triggered a regenerative response by Müller glia ${ }^{[138]}$. Independently, Ariga et al. ${ }^{[139]}$ and Walker et al. ${ }^{[140]}$ generated the Tg(rho:YFP-ntr)gmc500 transgenic line, which utilizes a $3.7 \mathrm{~kb}$ fragment of the zebrafish rhodopsin promoter to drive a $Y F P-n f s B$ transgene. The $\mathrm{Tg}(r h o: Y F P-n t r) g m c 500$ transgene was also expressed in all rod photoreceptors, indicating that the $3.7 \mathrm{~kb}$ promoter and the $1.2 \mathrm{~kb}$ promoter both contain proper elements for rod-specific expression. Exposing $\mathrm{Tg}$ (rho:YFP-ntr)gmc500 transgenic larvae to MTZ resulted in rod-specific death within $48 \mathrm{~h}$. Time-lapse in vivo imaging of demonstrated that peripheral macrophages and resident microglia rapidly transitioned to an amoeboid morphology following rod death in 5-7 dpf larvae ${ }^{[137]}$. No studies were performed on adult animals. The use of the MTZ/NTR system enables investigators to selectively ablate rods in an inducible manner. The ability to trigger acute damage to a specific cell type at a pre-determined time allows investigators to compare the regenerative response between acute injury and chronic degeneration models.

Tg(rho:Mmu.Rho_P23H-FLAG)uth $4 \mathrm{Tg}$

Transgenic models of adRP that express mutant forms of rhodopsin in rod photoreceptors have been made 
in mice ${ }^{[141-143]}$, rats $^{[144]}$, and frogs ${ }^{[145-148]}$. These models exhibit progressive rod degeneration and have proven invaluable toward understanding the mechanisms of degeneration caused by different pathogenic mutations in the rhodopsin gene. To determine if a zebrafish model of RP could be utilized to study the molecular signals stimulating regeneration, a construct was made that contained a $1.8 \mathrm{~kb}$ fragment of the zebrafish rhodopsin promoter to drive expression of a mouse rhodopsin carrying the $\mathrm{P} 23 \mathrm{H}$ mutation fused to a Cterminal Flag tag ${ }^{[149]}$. The $\mathrm{P} 23 \mathrm{H}$ mutation was chosen as it is the most frequent rhodopsin mutation to cause adRP and was the first mutation identified in humans ${ }^{[150]}$. The resulting stable transgenic line, $\mathrm{Tg}$ (rho:Mmu.Rho_P23H-FLAG)uth4Tg expressed the P23H-rhodopsin-FLAG beginning at 3 dpf. The mutant rhodopsin protein was mislocalized throughout the cell body and synapses in larval animals. Rod outer segments were shorter in larval stages but cones appeared normal. In adult transgenic animals, very few rods were observed and the $\mathrm{P} 23 \mathrm{H}$-rhodopsin-FLAG protein was significantly mislocalized in the remaining rods. Endogenous wild-type rhodopsin was also mislocalized, indicating that expression of the $\mathrm{P} 23 \mathrm{H}$-rhodopsin had deleterious effects on trafficking of outer segment proteins. Adult transgenic animals had a 3 -fold reduction in the number of nuclei in the ONL, indicating degeneration of rods. Interestingly, cone inner segments and outer segments were shorter in transgenic animals compared to adults, although the total number of Zpr1+ cones was unchanged. These results suggested that transgenic expression of a P23H-rhodopsin mutant causes secondary damage to cones. This differs from the rhodopsin (rh1-1) knockout zebrafish mutants, which had normal cone morphology ${ }^{[42]}$. At both $4 \mathrm{mpf}$ and $6 \mathrm{mpf}$, it was noticed that the number of proliferating cells (PCNA+) was considerably higher in the ONL of transgenic animals compared to wild-type. There was no signs of proliferation within the INL. Cell proliferation was confirmed by BrdU labeling and many of the BrdU+ cells also expressed rhodopsin, indicating that the newly post-mitotic cells were rods. Together, these results demonstrate that rod degeneration caused by expression of a $\mathrm{P} 23 \mathrm{H}$-rhodopsin transgene can initiate a regeneration response from rod precursors but not from Müller glia.

\section{PERSPECTIVES}

The mutants and transgenic models described herein represent a variety of human retinal dystrophy conditions, ranging from ciliopathies to RP to cone-rod dystrophy. As zebrafish also possesses the capacity to regenerate, it remains unclear why the response to progressive degeneration differs so greatly from acute damage. Inflammation is believed to be critical for the initial reprogramming of Müller glia ${ }^{[151]}$, but excess inflammation compromises survival of regenerated photoreceptors ${ }^{[152]}$. Whether chronic inflammation may limit Müller glia reprogramming remains unanswered. It is also known that Notch signaling suppresses regeneration ${ }^{[153,154]}$. Following acute injury, expression of notch 3 is significantly downregulated prior to Müller glia proliferation. Understanding potential differences in the transcriptional responses of Müller glia $^{[155]}$ and microglia ${ }^{[156]}$ to disease and injury will hopefully help answer why zebrafish do not regenerate in these IRD models.

\section{CONCLUSION}

The zebrafish represents an ideal genetic model to study the pathology of retinal degeneration in a cone-rich retina. The development of new genetic tools for genome editing allow investigators to target candidate genes of interest. Indeed, many of the models described herein were generated by genome editing technologies. The power of unbiased forward genetic screens thrust zebrafish into the scientific mainstream by uncovering genes essential for vertebrate development and function. In the future, more sophisticated or sensitive forward genetic screening approaches could be utilized to identify adult-onset phenotypes in a space- and cost-efficient manner that will reveal even more genes and pathways critical for the health and survival of photoreceptors. 


\section{DECLARATIONS}

\section{Authors' contributions}

The author contributed solely to the article.

\section{Availability of data and materials}

Not applicable.

\section{Financial support and sponsorship}

This work was supported by NIH grants R01-EY017037 and R01-EY030574 and a Doris and Jules Stein Professorship Award from Research to Prevent Blindness B.D.P. Additional support was provided by a P30 core grant (P30-EY025585), a Foundation Fighting Blindness (FFB) Center Grant, and an Unrestricted Award from Research to Prevent Blindness to the Cole Eye Institute. The funding bodies had no role in the design or writing of this manuscript.

\section{Ethical approval and consent to participate}

Not applicable.

\section{Conflicts of interest}

The author declared that there are no conflicts of interest.

\section{Consent for publication}

Not applicable.

\section{Copyright}

(C) The Author(s) 2022

\section{REFERENCES}

1. RetNet ${ }^{\mathrm{TM}}$ - The Retinal Information Network. Available from: https://sph.uth.edu/retnet/ [Last accessed on 15 Dec 2021$]$.

2. Hanany M, Rivolta C, Sharon D. Worldwide carrier frequency and genetic prevalence of autosomal recessive inherited retinal diseases. Proc Natl Acad Sci U S A 2020;117:2710-6. DOI PubMed PMC

3. Gong J, Cheung S, Fasso-Opie A, et al. The impact of inherited retinal diseases in the United States of America (US) and Canada from a cost-of-illness perspective. Clin Ophthalmol 2021;15:2855-66. DOI PubMed PMC

4. Edwards TL, Jolly JK, Groppe M, et al. Visual acuity after retinal gene therapy for choroideremia. N Engl J Med 2016;374:1996-8. DOI PubMed PMC

5. Bennett J, Wellman J, Marshall KA, et al. Safety and durability of effect of contralateral-eye administration of AAV2 gene therapy in patients with childhood-onset blindness caused by RPE65 mutations: a follow-on phase 1 trial. Lancet 2016;388:661-72. DOI PubMed PMC

6. Suzuki K, Tsunekawa Y, Hernandez-Benitez R, et al. In vivo genome editing via CRISPR/Cas9 mediated homology-independent targeted integration. Nature 2016;540:144-9. DOI PubMed PMC

7. Pearson RA, Barber AC, Rizzi M, et al. Restoration of vision after transplantation of photoreceptors. Nature 2012;485:99-103. DOI PubMed PMC

8. MacLaren RE, Pearson RA, MacNeil A, et al. Retinal repair by transplantation of photoreceptor precursors. Nature 2006;444:203-7. DOI PubMed

9. Sanges D, Simonte G, Di Vicino U, et al. Reprogramming Müller glia via in vivo cell fusion regenerates murine photoreceptors. $J$ Clin Invest 2016;126:3104-16. DOI PubMed PMC

10. Salman A, McClements ME, MacLaren RE. Insights on the regeneration potential of Müller glia in the mammalian retina. Cells 2021:10. DOI PubMed PMC

11. Jorstad NL, Wilken MS, Grimes WN, et al. Stimulation of functional neuronal regeneration from Müller glia in adult mice. Nature 2017;548:103-7. DOI PubMed PMC

12. Yao K, Qiu S, Wang YV, et al. Restoration of vision after de novo genesis of rod photoreceptors in mammalian retinas. Nature 2018;560:484-8. DOI PubMed PMC

13. Thummel R, Kassen SC, Enright JM, Nelson CM, Montgomery JE, Hyde DR. Characterization of Müller glia and neuronal progenitors during adult zebrafish retinal regeneration. Exp Eye Res 2008;87:433-44. DOI PubMed PMC

14. Vihtelic TS, Hyde DR. Light-induced rod and cone cell death and regeneration in the adult albino zebrafish (Danio rerio) retina. $J$ Neurobiol 2000;44:289-307. DOI PubMed 
15. Fausett BV, Goldman D. A role for alpha1 tubulin-expressing Müller glia in regeneration of the injured zebrafish retina. $J$ Neurosci 2006;26:6303-13. DOI PubMed PMC

16. Sherpa T, Fimbel SM, Mallory DE, et al. Ganglion cell regeneration following whole-retina destruction in zebrafish. Dev Neurobiol 2008;68:166-81. DOI PubMed PMC

17. Nelson CM, Gorsuch RA, Bailey TJ, Ackerman KM, Kassen SC, Hyde DR. Stat3 defines three populations of Müller glia and is required for initiating maximal Müller glia proliferation in the regenerating zebrafish retina. J Comp Neurol 2012;520:4294-311. DOI PubMed PMC

18. Qin Z, Barthel LK, Raymond PA. Genetic evidence for shared mechanisms of epimorphic regeneration in zebrafish. Proc Natl Acad Sci U S A 2009;106:9310-5. DOI PubMed PMC

19. Streisinger G, Singer F, Walker C, Knauber D, Dower N. Segregation analyses and gene-centromere distances in zebrafish. Genetics 1986;112:311-9. DOI PubMed PMC

20. Streisinger G, Walker C, Dower N, Knauber D, Singer F. Production of clones of homozygous diploid zebra fish (Brachydanio rerio). Nature 1981;291:293-6. DOI PubMed

21. Vaz R, Hofmeister W, Lindstrand A. Zebrafish models of neurodevelopmental disorders: limitations and benefits of current tools and techniques. Int J Mol Sci 2019:20. DOI PubMed PMC

22. Hong Y, Luo Y. Zebrafish model in ophthalmology to study disease mechanism and drug discovery. Pharmaceuticals (Basel) 2021:14. DOI PubMed PMC

23. Patton EE, Zon LI, Langenau DM. Zebrafish disease models in drug discovery: from preclinical modelling to clinical trials. Nat Rev Drug Discov 2021;20:611-28. DOI PubMed

24. Stewart KM, Walker SL, Baker AH, Riley PR, Brittan M. Hooked on heart regeneration: the zebrafish guide to recovery. Cardiovasc Res 2021. DOI PubMed

25. Houcke J, Marien V, Zandecki C, Seuntjens E, Ayana R, Arckens L. Modeling neuroregeneration and neurorepair in an aging context: the power of a teleost model. Front Cell Dev Biol 2021;9:619197. DOI

26. Wang X, Zhang JB, He KJ, Wang F, Liu CF. Advances of zebrafish in neurodegenerative disease: from models to drug discovery. Front Pharmacol 2021;12:713963. DOI PubMed PMC

27. Noel NCL, Nadolski NJ, Hocking JC, MacDonald IM, Allison WT. Progressive photoreceptor dysfunction and age-related macular degeneration-like features in rp111 mutant zebrafish. Cells 2020;9:2214. DOI PubMed PMC

28. Gross JM, Perkins BD. Zebrafish mutants as models for congenital ocular disorders in humans. Mol Reprod Dev 2008;75:547-55. DOI PubMed

29. Brockerhoff SE, Hurley JB, Janssen-Bienhold U, Neuhauss SC, Driever W, Dowling JE. A behavioral screen for isolating zebrafish mutants with visual system defects. Proc Natl Acad Sci U S A 1995;92:10545-9. DOI PubMed PMC

30. Neuhauss SC, Biehlmaier O, Seeliger MW, et al. Genetic disorders of vision revealed by a behavioral screen of 400 essential loci in zebrafish. J Neurosci 1999;19:8603-15. PubMed PMC

31. Gross JM, Perkins BD, Amsterdam A, et al. Identification of zebrafish insertional mutants with defects in visual system development and function. Genetics 2005;170:245-61. DOI PubMed PMC

32. Muto A, Orger MB, Wehman AM, et al. Forward genetic analysis of visual behavior in zebrafish. PLoS Genet 2005; 1:e66. DOI PubMed PMC

33. Li L, Dowling JE. A dominant form of inherited retinal degeneration caused by a non-photoreceptor cell-specific mutation. Proc Natl Acad Sci U S A 1997;94:11645-50. DOI PubMed PMC

34. Malicki J, Neuhauss SC, Schier AF, et al. Mutations affecting development of the zebrafish retina. Development 1996;123:263-73. PubMed

35. Fadool JM, Brockerhoff SE, Hyatt GA, Dowling JE. Mutations affecting eye morphology in the developing zebrafish (Danio rerio). Dev Genet 1997;20:288-95. DOI PubMed

36. Tsujikawa M, Malicki J. Intraflagellar transport genes are essential for differentiation and survival of vertebrate sensory neurons. Neuron 2004;42:703-16. DOI PubMed

37. Stearns G, Evangelista M, Fadool JM, Brockerhoff SE. A mutation in the cone-specific pde6 gene causes rapid cone photoreceptor degeneration in zebrafish. $J$ Neurosci 2007;27:13866-74. DOI PubMed PMC

38. Brockerhoff SE, Rieke F, Matthews HR, et al. Light stimulates a transducin-independent increase of cytoplasmic $\mathrm{Ca}^{2+}$ and suppression of current in cones from the zebrafish mutant nof. J Neurosci 2003;23:470-80. PubMed PMC

39. Wei X, Malicki J. nagie oko, encoding a MAGUK-family protein, is essential for cellular patterning of the retina. Nat Genet 2002;31:150-7. DOI PubMed

40. Omori Y, Malicki J. oko meduzy and related crumbs genes are determinants of apical cell features in the vertebrate embryo. Curr Biol 2006;16:945-57. DOI PubMed

41. Lessieur EM, Fogerty J, Gaivin RJ, Song P, Perkins BD. The ciliopathy gene ahi1 is required for zebrafish cone photoreceptor outer segment morphogenesis and survival. Invest Ophthalmol Vis Sci 2017;58:448-60. DOI PubMed PMC

42. Zelinka CP, Sotolongo-Lopez M, Fadool JM. Targeted disruption of the endogenous zebrafish rhodopsin locus as models of rapid rod photoreceptor degeneration. Mol Vis 2018;24:587-602. PubMed PMC

43. Nagashima M, Hitchcock PF. Inflammation regulates the multi-step process of retinal regeneration in zebrafish. Cells 2021;10:783. DOI PubMed PMC

44. Stella SL Jr, Geathers JS, Weber SR, et al. Neurodegeneration, neuroprotection and regeneration in the zebrafish retina. Cells 2021;10:633. DOI PubMed PMC 
45. Var SR, Byrd-Jacobs CA. Role of macrophages and microglia in zebrafish regeneration. Int J Mol Sci 2020:21. DOI PubMed PMC

46. Iribarne M. Inflammation induces zebrafish regeneration. Neural Regen Res 2021;16:1693-701. DOI PubMed PMC

47. Ganzen L, Venkatraman P, Pang CP, Leung YF, Zhang M. Utilizing zebrafish visual behaviors in drug screening for retinal degeneration. Int J Mol Sci 2017;18:1185. DOI PubMed PMC

48. Shi Y, Su Y, Lipschutz JH, Lobo GP. Zebrafish as models to study ciliopathies of the eye and kidney. Clin Nephrol Res 2017;1:6-9. PubMed PMC

49. Link BA, Collery RF. Zebrafish models of retinal disease. Annu Rev Vis Sci 2015;1:125-53. DOI PubMed

50. Fimbel SM, Montgomery JE, Burket CT, Hyde DR. Regeneration of inner retinal neurons after intravitreal injection of ouabain in zebrafish. J Neurosci 2007;27:1712-24. DOI PubMed PMC

51. Sherpa T, Lankford T, McGinn TE, et al. Retinal regeneration is facilitated by the presence of surviving neurons. Dev Neurobiol 2014;74:851-76. DOI PubMed PMC

52. Dixon-Salazar T, Silhavy JL, Marsh SE, et al. Mutations in the AHI1 gene, encoding jouberin, cause Joubert syndrome with cortical polymicrogyria. Am J Hum Genet 2004;75:979-87. DOI PubMed PMC

53. Ferland RJ, Eyaid W, Collura RV, et al. Abnormal cerebellar development and axonal decussation due to mutations in AHI1 in Joubert syndrome. Nat Genet 2004;36:1008-13. DOI PubMed

54. Hsiao YC, Tong ZJ, Westfall JE, Ault JG, Page-McCaw PS, Ferland RJ. Ahi1, whose human ortholog is mutated in Joubert syndrome, is required for Rab8a localization, ciliogenesis and vesicle trafficking. Hum Mol Genet 2009;18:3926-41. DOI PubMed PMC

55. Westfall JE, Hoyt C, Liu Q, et al. Retinal degeneration and failure of photoreceptor outer segment formation in mice with targeted deletion of the Joubert syndrome gene, Ahi1. J Neurosci 2010;30:8759-68. DOI PubMed PMC

56. Sohocki MM, Bowne SJ, Sullivan LS, et al. Mutations in a new photoreceptor-pineal gene on 17p cause Leber congenital amaurosis. Nat Genet 2000;24:79-83. DOI PubMed PMC

57. der Spuy J, Chapple JP, Clark BJ, Luthert PJ, Sethi CS, Cheetham ME. The Leber congenital amaurosis gene product AIPL1 is localized exclusively in rod photoreceptors of the adult human retina. Hum Mol Genet 2002;11:823-31. DOI PubMed

58. Hidalgo-de-Quintana J, Evans RJ, Cheetham ME, van der Spuy J. The Leber congenital amaurosis protein AIPL1 functions as part of a chaperone heterocomplex. Invest Ophthalmol Vis Sci 2008;49:2878-87. DOI PubMed PMC

59. Ramamurthy V, Roberts M, van den Akker F, Niemi G, Reh TA, Hurley JB. AIPL1, a protein implicated in Leber's congenital amaurosis, interacts with and aids in processing of farnesylated proteins. Proc Natl Acad Sci USA 2003;100:12630-5. DOI PubMed PMC

60. Sacristan-Reviriego A, Le HM, Georgiou M, et al. Clinical and functional analyses of AIPL1 variants reveal mechanisms of pathogenicity linked to different forms of retinal degeneration. Sci Rep 2020;10:17520. DOI PubMed PMC

61. Iribarne M, Hyde DR, Masai I. TNFalpha induces Müller glia to transition from non-proliferative gliosis to a regenerative response in mutant zebrafish presenting chronic photoreceptor degeneration. Front Cell Dev Biol 2019;7:296. DOI PubMed PMC

62. Stenkamp DL. The rod photoreceptor lineage of teleost fish. Prog Retin Eye Res 2011;30:395-404. DOI PubMed PMC

63. Katsanis N, Ansley SJ, Badano JL, et al. Triallelic inheritance in Bardet-Biedl syndrome, a Mendelian recessive disorder. Science 2001;293:2256-9. DOI PubMed

64. Beales PL, Elcioglu N, Woolf AS, Parker D, Flinter FA. New criteria for improved diagnosis of Bardet-Biedl syndrome: results of a population survey. J Med Genet 1999;36:437-46. PubMed PMC

65. Weihbrecht K, Goar WA, Pak T, et al. Keeping an eye on Bardet-Biedl syndrome: a comprehensive review of the role of BardetBiedl syndrome genes in the eye. Med Res Arch 2017;5:10.18103/mra.v5i9.1526. DOI PubMed PMC

66. Nachury MV, Loktev AV, Zhang Q, et al. A core complex of BBS proteins cooperates with the GTPase Rab8 to promote ciliary membrane biogenesis. Cell 2007;129:1201-13. DOI PubMed

67. Liu P, Lechtreck KF. The Bardet-Biedl syndrome protein complex is an adapter expanding the cargo range of intraflagellar transport trains for ciliary export. Proc Natl Acad Sci U S A 2018;115:E934-E43. DOI PubMed PMC

68. Datta P, Allamargot C, Hudson JS, et al. Accumulation of non-outer segment proteins in the outer segment underlies photoreceptor degeneration in Bardet-Biedl syndrome. Proc Natl Acad Sci U S A 2015;112:E4400-9. DOI PubMed PMC

69. Song P, Fogerty J, Cianciolo LT, Stupay R, Perkins BD. Cone photoreceptor degeneration and neuroinflammation in the zebrafish Bardet-Biedl syndrome 2 (bbs2) mutant does not lead to retinal regeneration. Front Cell Dev Biol 2020;8:578528. DOI

70. Grimes DT, Boswell CW, Morante NF, Henkelman RM, Burdine RD, Ciruna B. Zebrafish models of idiopathic scoliosis link cerebrospinal fluid flow defects to spine curvature. Science 2016;352:1341-4. DOI PubMed PMC

71. Rachel RA, Yamamoto EA, Dewanjee MK, et al. CEP290 alleles in mice disrupt tissue-specific cilia biogenesis and recapitulate features of syndromic ciliopathies. Hum Mol Genet 2015;24:3775-91. DOI PubMed PMC

72. Gorden NT, Arts HH, Parisi MA, et al. CC2D2A is mutated in Joubert syndrome and interacts with the ciliopathy-associated basal body protein CEP290. Am J Hum Genet 2008;83:559-71. DOI PubMed PMC

73. Schouteden C, Serwas D, Palfy M, Dammermann A. The ciliary transition zone functions in cell adhesion but is dispensable for axoneme assembly in C. elegans. J Cell Biol 2015;210:35-44. DOI PubMed PMC

74. Chang B, Khanna H, Hawes N, et al. In-frame deletion in a novel centrosomal/ciliary protein CEP290/NPHP6 perturbs its interaction with RPGR and results in early-onset retinal degeneration in the rd16 mouse. Hum Mol Genet 2006;15:1847-57. DOI PubMed PMC

75. Li C, Jensen VL, Park K, et al. MKS5 and CEP290 dependent assembly pathway of the ciliary transition zone. PLoS Biol 2016;14:e1002416. DOI PubMed PMC

76. Garcia-Gonzalo FR, Corbit KC, Sirerol-Piquer MS, et al. A transition zone complex regulates mammalian ciliogenesis and ciliary 
membrane composition. Nat Genet 2011;43:776-84. DOI PubMed PMC

77. Coppieters F, Lefever S, Leroy BP, De Baere E. CEP290, a gene with many faces: mutation overview and presentation of CEP290base. Hum Mutat 2010;31:1097-108. DOI PubMed

78. Reiter JF, Leroux MR. Genes and molecular pathways underpinning ciliopathies. Nat Rev Mol Cell Biol 2017;18:533-47. DOI PubMed PMC

79. den Hollander AI, Koenekoop RK, Yzer S, et al. Mutations in the CEP290 (NPHP6) gene are a frequent cause of Leber congenital amaurosis. Am J Hum Genet 2006;79:556-61. DOI PubMed PMC

80. Feldhaus B, Weisschuh N, Nasser F, et al. CEP290 mutation spectrum and delineation of the associated phenotype in a large German cohort: a monocentric study. Am J Ophthalmol 2020;211:142-50. DOI PubMed

81. Lessieur EM, Song P, Nivar GC, et al. Ciliary genes arl13b, ahi1 and cc2d2a differentially modify expression of visual acuity phenotypes but do not enhance retinal degeneration due to mutation of cep290 in zebrafish. PLoS One 2019;14:e0213960. DOI

82. Stawicki TM, Hernandez L, Esterberg R, et al. Cilia-associated genes play differing roles in aminoglycoside-induced hair cell death in zebrafish. G3 (Bethesda) 2016;6:2225-35. DOI PubMed PMC

83. Cardenas-Rodriguez M, Austin-Tse C, Bergboer JGM, et al. Genetic compensation for cilia defects in cep290 mutants by upregulation of cilia-associated small GTPases. J Cell Sci 2021:134. DOI PubMed PMC

84. Tuson M, Marfany G, Gonzalez-Duarte R. Mutation of CERKL, a novel human ceramide kinase gene, causes autosomal recessive retinitis pigmentosa (RP26). Am J Hum Genet 2004;74:128-38. DOI PubMed PMC

85. Bornancin F, Mechtcheriakova D, Stora S, et al. Characterization of a ceramide kinase-like protein. Biochim Biophys Acta 2005; 1687:31-43. DOI PubMed

86. Graf C, Niwa S, Müller M, Kinzel B, Bornancin F. Wild-type levels of ceramide and ceramide-1-phosphate in the retina of ceramide kinase-like-deficient mice. Biochem Biophys Res Commun 2008;373:159-63. DOI PubMed

87. Aleman TS, Soumittra N, Cideciyan AV, et al. CERKL mutations cause an autosomal recessive cone-rod dystrophy with inner retinopathy. Invest Ophthalmol Vis Sci 2009;50:5944-54. DOI PubMed

88. Yu S, Li C, Biswas L, et al. CERKL gene knockout disturbs photoreceptor outer segment phagocytosis and causes rod-cone dystrophy in zebrafish. Hum Mol Genet 2017;26:2335-45. DOI PubMed

89. Arai Y, Maeda A, Hirami Y, et al. Retinitis pigmentosa with EYS mutations is the most prevalent inherited retinal dystrophy in Japanese populations. J Ophthalmol 2015;2015:819760. DOI PubMed PMC

90. Abd El-Aziz MM, Barragan I, O'Driscoll CA, et al. EYS, encoding an ortholog of Drosophila spacemaker, is mutated in autosomal recessive retinitis pigmentosa. Nat Genet 2008;40:1285-7. DOI PubMed PMC

91. Abd El-Aziz MM, O'Driscoll CA, Kaye RS, et al. Identification of novel mutations in the ortholog of Drosophila eyes shut gene (EYS) causing autosomal recessive retinitis pigmentosa. Invest Ophthalmol Vis Sci 2010;51:4266-72. DOI PubMed

92. Yu M, Liu Y, Li J, et al. Eyes shut homolog is required for maintaining the ciliary pocket and survival of photoreceptors in zebrafish. Biol Open 2016;5:1662-73. DOI PubMed PMC

93. Lu Z, Hu X, Liu F, et al. Ablation of EYS in zebrafish causes mislocalisation of outer segment proteins, F-actin disruption and conerod dystrophy. Sci Rep 2017;7:46098. DOI PubMed PMC

94. Messchaert M, Dona M, Broekman S, et al. Eyes shut homolog is important for the maintenance of photoreceptor morphology and visual function in zebrafish. PLoS One 2018;13:e0200789. DOI PubMed PMC

95. Collin RW, Safieh C, Littink KW, et al. Mutations in C2ORF71 cause autosomal-recessive retinitis pigmentosa. Am J Hum Genet 2010;86:783-8. DOI PubMed PMC

96. Nishimura DY, Baye LM, Perveen R, et al. Discovery and functional analysis of a retinitis pigmentosa gene, C2ORF71. Am J Hum Genet 2010;86:686-95. DOI PubMed PMC

97. Corral-Serrano JC, Lamers IJC, van Reeuwijk J, et al. PCARE and WASF3 regulate ciliary F-actin assembly that is required for the initiation of photoreceptor outer segment disk formation. Proc Natl Acad Sci U S A 2020;117:9922-31. DOI PubMed PMC

98. Corral-Serrano JC, Messchaert M, Dona M, et al. C2orf71a/pcare1 is important for photoreceptor outer segment morphogenesis and visual function in zebrafish. Sci Rep 2018;8:9675. DOI PubMed PMC

99. Arshavsky VY, Burns ME. Photoreceptor signaling: supporting vision across a wide range of light intensities. J Biol Chem 2012;287:1620-6. DOI PubMed PMC

100. Arshavsky VY, Burns ME. Current understanding of signal amplification in phototransduction. Cell Logist 2014;4:e29390. DOI PubMed PMC

101. Piriev NI, Viczian AS, Ye J, Kerner B, Korenberg JR, Farber DB. Gene structure and amino acid sequence of the human cone photoreceptor cGMP-phosphodiesterase alpha' subunit (PDEA2) and its chromosomal localization to 10q24. Genomics 1995;28:42935. DOI PubMed

102. Huang SH, Pittler SJ, Huang X, Oliveira L, Berson EL, Dryja TP. Autosomal recessive retinitis pigmentosa caused by mutations in the alpha subunit of rod cGMP phosphodiesterase. Nat Genet 1995;11:468-71. DOI PubMed

103. Thiadens AA, den Hollander AI, Roosing S, et al. Homozygosity mapping reveals PDE6C mutations in patients with early-onset cone photoreceptor disorders. Am J Hum Genet 2009;85:240-7. DOI PubMed PMC

104. Chang B, Grau T, Dangel S, et al. A homologous genetic basis of the murine cpfl1 mutant and human achromatopsia linked to mutations in the PDE6C gene. Proc Natl Acad Sci U S A 2009;106:19581-6. DOI PubMed PMC

105. Nishiwaki Y, Komori A, Sagara H, et al. Mutation of cGMP phosphodiesterase 6alpha'-subunit gene causes progressive degeneration of cone photoreceptors in zebrafish. Mech Dev 2008;125:932-46. DOI PubMed

106. Nishimura T, Kato K, Yamaguchi T, Fukata Y, Ohno S, Kaibuchi K. Role of the PAR-3-KIF3 complex in the establishment of 
neuronal polarity. Nat Cell Biol 2004;6:328-34. DOI PubMed

107. Crouzier L, Diez C, Richard EM, et al. Loss of Pde6a induces rod outer segment shrinkage and visual alterations in pde6a(Q70X) mutant zebrafish, a relevant model of retinal dystrophy. Front Cell Dev Biol 2021;9:675517. DOI PubMed PMC

108. Emran F, Rihel J, Dowling JE. A behavioral assay to measure responsiveness of zebrafish to changes in light intensities. J Vis Exp 2008;(20):923. DOI PubMed PMC

109. Kaplan J, Bonneau D, Frezal J, Munnich A, Dufier JL. Clinical and genetic heterogeneity in retinitis pigmentosa. Hum Genet 1990;85:635-42. DOI PubMed

110. Pelletier V, Jambou M, Delphin N, et al. Comprehensive survey of mutations in RP2 and RPGR in patients affected with distinct retinal dystrophies: genotype-phenotype correlations and impact on genetic counseling. Hum Mutat 2007;28:81-91. DOI PubMed

111. Grayson C, Bartolini F, Chapple JP, et al. Localization in the human retina of the X-linked retinitis pigmentosa protein RP2, its homologue cofactor C and the RP2 interacting protein Arl3. Hum Mol Genet 2002;11:3065-74. DOI PubMed

112. Veltel S, Gasper R, Eisenacher E, Wittinghofer A. The retinitis pigmentosa 2 gene product is a GTPase-activating protein for Arf-like 3. Nat Struct Mol Biol 2008;15:373-80. DOI PubMed

113. Evans RJ, Schwarz N, Nagel-Wolfrum K, Wolfrum U, Hardcastle AJ, Cheetham ME. The retinitis pigmentosa protein RP2 links pericentriolar vesicle transport between the Golgi and the primary cilium. Hum Mol Genet 2010;19:1358-67. DOI PubMed

114. Liu F, Chen J, Yu S, et al. Knockout of RP2 decreases GRK1 and rod transducin subunits and leads to photoreceptor degeneration in zebrafish. Hum Mol Genet 2015;24:4648-59. DOI PubMed

115. Roepman R, Bernoud-Hubac N, Schick DE, et al. The retinitis pigmentosa GTPase regulator (RPGR) interacts with novel transportlike proteins in the outer segments of rod photoreceptors. Hum Mol Genet 2000;9:2095-105. DOI PubMed

116. Boylan JP, Wright AF. Identification of a novel protein interacting with RPGR. Hum Mol Genet 2000;9:2085-93. DOI PubMed

117. Dryja TP, Adams SM, Grimsby JL, et al. Null RPGRIP1 alleles in patients with Leber congenital amaurosis. Am J Hum Genet 2001;68:1295-8. DOI PubMed PMC

118. Gerber S, Perrault I, Hanein S, et al. Complete exon-intron structure of the RPGR-interacting protein (RPGRIP1) gene allows the identification of mutations underlying Leber congenital amaurosis. Eur J Hum Genet 2001;9:561-71. DOI PubMed

119. Hameed A, Abid A, Aziz A, Ismail M, Mehdi SQ, Khaliq S. Evidence of RPGRIP1 gene mutations associated with recessive conerod dystrophy. J Med Genet 2003;40:616-9. DOI PubMed PMC

120. Hong DH, Yue G, Adamian M, Li T. Retinitis pigmentosa GTPase regulator (RPGRr)-interacting protein is stably associated with the photoreceptor ciliary axoneme and anchors RPGR to the connecting cilium. J Biol Chem 2001;276:12091-9. DOI PubMed

121. Castagnet P, Mavlyutov T, Cai Y, Zhong F, Ferreira P. RPGRIP1s with distinct neuronal localization and biochemical properties associate selectively with RanBP2 in amacrine neurons. Hum Mol Genet 2003;12:1847-63. DOI PubMed

122. Zhao Y, Hong DH, Pawlyk B, et al. The retinitis pigmentosa GTPase regulator (RPGR) - interacting protein: subserving RPGR function and participating in disk morphogenesis. Proc Natl Acad Sci U S A 2003;100:3965-70. DOI PubMed PMC

123. Raghupathy RK, Zhang X, Liu F, et al. Rpgrip1 is required for rod outer segment development and ciliary protein trafficking in zebrafish. Sci Rep 2017;7:16881. DOI PubMed PMC

124. Palczewski K, Kumasaka T, Hori T, et al. Crystal structure of rhodopsin: a G protein-coupled receptor. Science 2000;289:739-45. DOI PubMed

125. Sullivan LS, Bowne SJ, Birch DG, et al. Prevalence of disease-causing mutations in families with autosomal dominant retinitis pigmentosa: a screen of known genes in 200 families. Invest Ophthalmol Vis Sci 2006;47:3052-64. DOI PubMed PMC

126. Sullivan LS, Bowne SJ, Reeves MJ, et al. Prevalence of mutations in eyeGENE probands with a diagnosis of autosomal dominant retinitis pigmentosa. Invest Ophthalmol Vis Sci 2013;54:6255-61. DOI PubMed PMC

127. Dryja TP, McGee TL, Hahn LB, et al. Mutations within the rhodopsin gene in patients with autosomal dominant retinitis pigmentosa. N Engl J Med 1990;323:1302-7. DOI PubMed

128. Morrow JM, Lazic S, Chang BS. A novel rhodopsin-like gene expressed in zebrafish retina. Vis Neurosci 2011;28:325-35. DOI PubMed

129. Morrow JM, Lazic S, Dixon Fox M, et al. A second visual rhodopsin gene, rh1-2, is expressed in zebrafish photoreceptors and found in other ray-finned fishes. J Exp Biol 2017;220:294-303. DOI PubMed

130. Morris AC, Schroeter EH, Bilotta J, Wong RO, Fadool JM. Cone survival despite rod degeneration in XOPS-mCFP transgenic zebrafish. Invest Ophthalmol Vis Sci 2005;46:4762-71. DOI PubMed PMC

131. Tam BM, Moritz OL, Hurd LB, Papermaster DS. Identification of an outer segment targeting signal in the $\mathrm{COOH}$ terminus of rhodopsin using transgenic Xenopus laevis. J Cell Biol 2000;151:1369-80. DOI PubMed PMC

132. Kay JN, Roeser T, Mumm JS, et al. Transient requirement for ganglion cells during assembly of retinal synaptic layers. Development 2004;131:1331-42. DOI PubMed

133. Fadool JM. Development of a rod photoreceptor mosaic revealed in transgenic zebrafish. Dev Biol 2003;258:277-90. DOI PubMed

134. Morris AC, Scholz TL, Brockerhoff SE, Fadool JM. Genetic dissection reveals two separate pathways for rod and cone regeneration in the teleost retina. Dev Neurobiol 2008;68:605-19. DOI PubMed PMC

135. Morris AC, Forbes-Osborne MA, Pillai LS, Fadool JM. Microarray analysis of XOPS-mCFP zebrafish retina identifies genes associated with rod photoreceptor degeneration and regeneration. Invest Ophthalmol Vis Sci 2011;52:2255-66. DOI PubMed PMC

136. Babino D, Perkins BD, Kindermann A, Oberhauser V, von Lintig J. The role of 11-cis-retinyl esters in vertebrate cone vision. FASEB J 2015;29:216-26. DOI PubMed PMC

137. White DT, Sengupta S, Saxena MT, et al. Immunomodulation-accelerated neuronal regeneration following selective rod photoreceptor cell ablation in the zebrafish retina. Proc Natl Acad Sci U S A 2017;114:E3719-E28. DOI PubMed PMC 
138. Montgomery JE, Parsons MJ, Hyde DR. A novel model of retinal ablation demonstrates that the extent of rod cell death regulates the origin of the regenerated zebrafish rod photoreceptors. J Comp Neurol 2010;518:800-14. DOI PubMed PMC

139. Ariga J, Walker SL, Mumm JS. Multicolor time-lapse imaging of transgenic zebrafish: visualizing retinal stem cells activated by targeted neuronal cell ablation. J Vis Exp 2010;(43):2093. DOI PubMed PMC

140. Walker SL, Ariga J, Mathias JR, et al. Automated reporter quantification in vivo: high-throughput screening method for reporterbased assays in zebrafish. PLoS One 2012;7:e29916. DOI PubMed PMC

141. Chang B, Hawes NL, Hurd RE, Davisson MT, Nusinowitz S, Heckenlively JR. Retinal degeneration mutants in the mouse. Vision Res 2002;42:517-25. DOI PubMed

142. Olsson JE, Gordon JW, Pawlyk BS, et al. Transgenic mice with a rhodopsin mutation (Pro23His): a mouse model of autosomal dominant retinitis pigmentosa. Neuron 1992;9:815-30. DOI PubMed

143. Sakami S, Maeda T, Bereta G, et al. Probing mechanisms of photoreceptor degeneration in a new mouse model of the common form of autosomal dominant retinitis pigmentosa due to P23H opsin mutations. J Biol Chem 2011;286:10551-67. DOI PubMed PMC

144. Lewin AS, Drenser KA, Hauswirth WW, et al. Ribozyme rescue of photoreceptor cells in a transgenic rat model of autosomal dominant retinitis pigmentosa. Nat Med 1998;4:967-71. DOI PubMed

145. Tam BM, Moritz OL. Characterization of rhodopsin P23H-induced retinal degeneration in a Xenopus laevis model of retinitis pigmentosa. Invest Ophthalmol Vis Sci 2006;47:3234-41. DOI PubMed

146. Tam BM, Moritz OL. Dark rearing rescues P23H rhodopsin-induced retinal degeneration in a transgenic Xenopus laevis model of retinitis pigmentosa: a chromophore-dependent mechanism characterized by production of N-terminally truncated mutant rhodopsin. J Neurosci 2007;27:9043-53. DOI PubMed PMC

147. Tam BM, Moritz OL. The role of rhodopsin glycosylation in protein folding, trafficking, and light-sensitive retinal degeneration. $J$ Neurosci 2009;29:15145-54. DOI PubMed PMC

148. Tam BM, Qazalbash A, Lee HC, Moritz OL. The dependence of retinal degeneration caused by the rhodopsin P23H mutation on light exposure and vitamin a deprivation. Invest Ophthalmol Vis Sci 2010;51:1327-34. DOI PubMed

149. Santhanam A, Shihabeddin E, Atkinson JA, Nguyen D, Lin YP, O'Brien J. A zebrafish model of retinitis pigmentosa shows continuous degeneration and regeneration of rod photoreceptors. Cells 2020;9:2242. DOI PubMed PMC

150. Dryja TP, McGee TL, Reichel E, et al. A point mutation of the rhodopsin gene in one form of retinitis pigmentosa. Nature 1990;343:364-6. DOI PubMed

151. Conedera FM, Pousa AMQ, Mercader N, Tschopp M, Enzmann V. Retinal microglia signaling affects Müller cell behavior in the zebrafish following laser injury induction. Glia 2019;67:1150-66. DOI PubMed

152. Silva NJ, Nagashima M, Li J, et al. Inflammation and matrix metalloproteinase 9 (Mmp-9) regulate photoreceptor regeneration in adult zebrafish. Glia 2020;68:1445-65. DOI PubMed PMC

153. Conner C, Ackerman KM, Lahne M, Hobgood JS, Hyde DR. Repressing notch signaling and expressing TNFalpha are sufficient to mimic retinal regeneration by inducing Müller glial proliferation to generate committed progenitor cells. J Neurosci 2014;34:1440319. DOI PubMed PMC

154. Sahu A, Devi S, Jui J, Goldman D. Notch signaling via Hey1 and Id2b regulates Müller glia's regenerative response to retinal injury. Glia 2021;69:2882-98. DOI PubMed PMC

155. Hoang T, Wang J, Boyd P, et al. Gene regulatory networks controlling vertebrate retinal regeneration. Science 2020;370:eabb8598. DOI PubMed PMC

156. Mitchell DM, Sun C, Hunter SS, New DD, Stenkamp DL. Regeneration associated transcriptional signature of retinal microglia and macrophages. Sci Rep 2019;9:4768. DOI PubMed PMC 